\title{
Decontamination Effect of Zinc Oxide Nanoparticles, Rosmarinic Acid and Anatolian Propolis on Foodborne Bacteria
}

\author{
Tahsin Onur Kevenk ${ }^{1, a, *}$, Zeki Aras ${ }^{2, b}$ \\ ${ }^{1}$ Department of Food Hygiene and Technology, Faculty of Veterinary Medicine, Aksaray University, 68100 Aksaray, Turkey. \\ ${ }^{2}$ Department of Microbiology, Faculty of Veterinary Medicine, Aksaray University, 68100 Aksaray, Turkey.
}

*Corresponding author

\begin{tabular}{l|l} 
A R T I C L E I N F O & A B S T R A C T \\
\hline $\begin{array}{l}\text { Research Article } \\
\text { Received : 26/11/2021 } \\
\text { Accepted : } 12 / 01 / 2022\end{array}$ & $\begin{array}{l}\text { Zinc oxide (ZnO) has been used in the pharmaceutical, cosmetic, paint, textile, and food industries } \\
\text { to coat surfaces and absorb UV rays. As a result of its antimicrobial properties in nanoscale, it may } \\
\text { be a promising chemical for decontamination. Zinc oxide nanoparticles (ZnO-NPs) are generally } \\
\text { considered safe (GRAS) for their stability under challenging processing conditions. Our study } \\
\text { investigated the antimicrobial activities of rosmarinic acid and propolis, prepared at different } \\
\text { concentrations together with ZnO-NPs. For this purpose, six leading foodborne pathogens and a } \\
\text { starter culture were chosen. The invitro decontamination effects of ZnO-NPs, rosmarinic acid, and } \\
\text { propolis combinations on selected bacteria in the first 24 hours were demonstrated by bacterial } \\
\text { counts at regular intervals. According to our results, propolis and ZnO-NPs showed remarkable } \\
\text { results together. In addition, rosmarinic acid's lower concentrations were also found to induce the } \\
\text { decontamination effect of ZnO-NPs. Although the antimicrobial effect of ZnO-NPs, when used } \\
\text { alone, was less than when used in combination, it was still found to be sufficient. }\end{array}$ \\
$\begin{array}{l}\text { Keywords: } \\
\text { Zinc oxide } \\
\text { Nanoparticles }\end{array}$ &
\end{tabular}

Rosmarinic acid

Propolis

Decontamination

tahsinonurkevenk@aksaray.edu.tr (iDhtps://orcid.org/0000-0003-2519-8060| b@zekiaras@hotmail.com

\section{Introduction}

Particles which dimensions between 1-100 nanometers $(\mathrm{nm})$ are termed nanoparticles. It is known that large surface areas and unique physicochemical properties are displayed as the source of nanoparticles powerful antimicrobial effects (Bharat et al., 2019). In the last decade, correspondingly with contemporary developments in the understanding of hygiene, the importance of nanoparticles began to increase globally. Nanoparticles have started to appear in many areas as a new, effective and alternative weapon in the fight against zoonotic diseases, one of the most critical public health problems today (Deshmukh et al., 2019). Today, disinfectants such as alcohols, quaternary ammonium compounds, aldehydes, and oxidizing agents are frequently used to improve hygienic conditions and combat zoonotic agents. However, corrosive character, not being environmentally friendly, and losing their effectiveness over time are important disadvantages of these chemicals. Nanoparticles, which are not thought to have the disadvantages mentioned above, are accepted as a new approach in this field (Gupta and Silver, 1998).

According to their core's character, nanoparticles are divided into two main groups: inorganic and organic. Zinc oxide nanoparticles (ZnO-NPs) are placed in the inorganic group with other metals and metal oxide members (Al, Bi, $\mathrm{Co}, \mathrm{Cu}, \mathrm{Au}, \mathrm{Fe}, \mathrm{In}, \mathrm{Mo}, \mathrm{Ni}, \mathrm{Ag}, \mathrm{Sn}, \mathrm{Ti}, \mathrm{W}, \mathrm{Al}_{2} \mathrm{O}_{3}, \mathrm{CeO}_{2}$, $\mathrm{CuO}, \mathrm{Cu}_{2} \mathrm{O}, \mathrm{In}_{2} \mathrm{O}_{3}, \mathrm{La}_{2} \mathrm{O}_{3}, \mathrm{MgO}, \mathrm{NiO}, \mathrm{TiO}_{2}, \mathrm{SnO}_{2}, \mathrm{ZrO}_{2}$ ) (Shrestha et al., 2013). Zinc oxide nanoparticles which have a solid antibacterial aspect, are widely used in many sectors such as fabric, pharmaceutical, and food industries due to their durable, stable, and reliable character under challenging conditions (Raghupathi et al., 2011).

Rosmarinic acid (RA) originates from plants belonging to the Lamiaceae family including, Rosmarinus officinalis (rosemary). It has been reported that RA has impressive biological effects such as antiviral, antibacterial, antioxidant, antiallergic, and anti-inflammatory activities (Nadeem et al., 2019). Several studies showed that the antibacterial effect of RA on $S$. aureus, methicillin- 
resistant S. aureus (MRSA), Enterobacteriaceae spp., Pseudomonas spp., lactic acid bacteria, yeast and mold, and Listeria monocytogenes had been exerted (Ekambaram et al., 2016; Raeisi et al., 2016; Zhuang et al., 2016). RA is also advised as natural food conservative due to its antimicrobial properties (Zhang et al., 2021).

The word "Propolis" originated from Greek, means entrance of the city. It is also known as bee glue, a sticky, resinous chemical used to defend the hive by honeybees (Apis mellifera). It is naturally in antimicrobial character, and propolis has been used for this purpose since ancient Greek and Egyptian times (Buchta et al., 2011; SimoneFinstrom et al., 2017; Wagh, 2013). The antibacterial effect of propolis is well examined by numerous studies on both gram-negative and positive bacteria. Today, where multidrug resistance is shown as one of the most critical public health problems, a unique chemical like propolis is thought to be an essential solution to this problem. The antibacterial effect of propolis on resistant bacteria such as $S$. aureus and $E$. coli has been proven by many studies (Darwish et al., 2010).

The study aims (i) Investigation of in-vitro decontamination effect of ZnO-NPs and combinations of $\mathrm{ZnO}-\mathrm{NPs}$, rosmarinic acid, and propolis on $E$. coli O157:H7 ATCC 43895, Salmonella Typhimurium, Proteus mirabilis, S. aureus ATCC 46300, $L$. monocytogenes ATCC 7644, B. cereus ATCC 10987 and a starter culture Lactobacillus delbrueckii subsp. bulgaricus ATCC 11842 (ii) Understanding the antibacterial efficiency of Anatolian Propolis, (iii) Understanding the most appropriate concentration and application method of $\mathrm{ZnO}-\mathrm{NPs}$, rosmarinic acid, and propolis.

\section{Materials and Methods}

\section{Materials}

\section{Preparation of Bacterial Strains}

In the present study, three gram-negative and three gram-positive foodborne pathogens (E. coli O157:H7 ATCC 43895 (EC), Salmonella Typhimurium (ST), Proteus mirabilis (PT), Staphylococcus aureus ATCC 46300 (SA), Listeria monocytogenes ATCC 7644 (LM), B. cereus ATCC 10987 (BC) and a starter culture (Lactobacillus delbrueckii subsp. bulgaricus ATCC 11842 (LB)) were used for understanding the decontamination effect of $\mathrm{ZnO}-\mathrm{NPs}$, rosmarinic acid, and propolis. All strains were kept at $-20^{\circ} \mathrm{C}$ before activating in Brain Heart Infusion Broth (BHI, HiMedia M210). All bacterial strains were cultured under optimal growth conditions recommended by the International Organization for Standardization (ISO). In this sense, ISO 16654, ISO 6888, ISO 9232 conditions were used for E. coli O157:H7, Staphylococcus aureus, and Lactobacillus delbrueckii subsp. bulgaricus, respectively.

\section{Preparation of $\mathrm{ZnO}$-NPs Solution}

$1 \mathrm{M}$ stock solution of nanopowder $\mathrm{ZnO}$, which has $<50$ $\mu$ particle size and $10.8 \mathrm{~m}^{2} / \mathrm{g}$ surface area (Sigma-Aldrich 677450) diluted in Maximum Recovery Diluent (MRD, Merck 146809). Within the scope of the study, experimental groups were contained $10 \mathrm{mmol} / \mathrm{L}$ concentration of $\mathrm{ZnO}-\mathrm{NPs}$ in diluting solution.

Preparation of 1\% Rosmarinic Acid

The rosmarinic acid (Merck 536954) was dissolved in MRD at $1 \%$ final concentration and then used for inoculation.

\section{Extraction of Propolis}

Approximately $30 \mathrm{~g}$ propolis was obtained from a honeybee facility in Muğla (Southwest of Turkey). Firstly, the propolis was sliced into small pieces. Then it was ground into flour using a blender. For extraction of propolis, $80 \%$ ethanol was used for $48 \mathrm{~h}$ at room temperature. Then, ethanol - propolis mixture was filtered with Whatman No. 4 paper and concentrated by a rotary evaporator to get pure extract (Jafarzadeh Kashi et al., 2011). The extracted pure propolis was dissolved with $80 \%$ ethanol at $200 \mathrm{mg} / \mathrm{mL}$ final concentration. This stock solution was diluted in MRD (1/10) for experimental analysis in the final concentration.

All chemicals were filter-sterilized using $0.22 \mu \mathrm{m}$ filters (Minisart ${ }^{\circledR}$ Syringe Filters. Sartorious) and stored at $4^{\circ} \mathrm{C}$.

Determination of Experimental Groups

A total of six experimental groups were formed. These groups were included $\mathrm{ZnO}-\mathrm{NPs}$, rosmarinic acid, and propolis separately, $\mathrm{ZnO}-\mathrm{NPs} /$ propolis, $\mathrm{ZnO}$ NPs/rosmarinic acid, and ZnO-NPs/propolis/rosmarinic acid in combinations.

\section{Methods}

Broth dilution method was used for the investigation of in-vitro antibacterial activity of ZnO-NPs, rosmarinic acid, and propolis. The bacterial strains used in the study were stored at $-20^{\circ} \mathrm{C}$ before activating in BHI by incubating at $37^{\circ} \mathrm{C}$ for $24 \mathrm{~h}$. Then, tested bacteria were plated onto Plate Count Agar (PCA, Merck 105463). After this, the bacterial turbidity was adjusted to $0.5 \mathrm{McF}$ arland $\left(\sim 1.5 \times 10^{8}\right)$ in the MRD, which also contains antibacterial chemicals in final concentrations (McFarland Biosan DEN-1). Then, the antibacterial effect of chemicals and their combinations were investigated by a counting procedure at $0,1^{\text {st }}, 2^{\text {nd }}, 4^{\text {th }}$, $8^{\text {th }}, 12^{\text {th }}$, and $24^{\text {th }}$ hours using the PCA. Enumeration of microorganisms was accomplished according to ISO 48331 method by pour plate technic (ISO, 2014).

\section{Results}

In the present study, the decontamination effect of 10 $\mathrm{mmol} / \mathrm{L} \mathrm{ZnO}-\mathrm{NPs}(<50 \mu), 1 \%$ rosmarinic acid, and 20 $\mathrm{mg} / \mathrm{mL}$ propolis on important foodborne bacteria was examined. For this purpose, a total of six different experimental groups were formed. At 0-hour, the bacterial turbidity was adjusted to 0.5 McFarland $\left(\sim 1.5 \times 10^{8}\right.$ $\mathrm{CFU} / \mathrm{mL})$ in the MRD in all test groups and a counting process was performed to control the initial load.

In the first group, where only the decontamination effect of ZnO-NPs was determined, after 24 hours, bacterial reduction of EC, ST, PM, SA, LM, BC, and LB were calculated as $3.61,3.55,3.9,3.43,3.3,3.0$, and 3.44 Log CFU/mL, respectively. In the second group, where only the decontamination effect of rosmarinic acid was investigated, the bacterial reduction on EC, ST, PM, SA, LM, BC, and LB were 2.22, 2.17, 1.99, 2.07, 2.0, 2.05, and $1.85 \mathrm{Log} C F U / \mathrm{mL}$, respectively. In the third group, where only the decontamination effect of propolis was inspected, the bacterial reduction on EC, ST, PM, SA, LM, BC, and LB were 3.95, 4.0, 3.7 , 3.67, 3.5, 3.2, and 3.05 Log CFU/mL, respectively. In the fourth group, where the decontamination effect of $\mathrm{ZnO}-\mathrm{NPs} /$ propolis combination was measured, the bacterial reduction on EC, ST, PM, SA, LM, BC, and LB 
were $5.52,5.75,5.40,5.01,4.95,4.65$, and $5.26 \mathrm{Log}$ $\mathrm{CFU} / \mathrm{mL}$, respectively. In the fifth group, where the decontamination effect of ZnO-NPs/rosmarinic acid combination was determined, the bacterial reduction on $\mathrm{EC}$, ST, PM, SA, LM, BC, and LB were 4.21, 4.15, 4.10, 4.05, 3.95, 4.05, and 4.20 Log CFU/mL, respectively. Finally, in the sixth group, where the decontamination effect of $\mathrm{ZnO}$ NPs/rosmarinic acid/propolis combination was researched, the bacterial reduction on EC, ST, PM, SA, LM, BC, and LB were $6.54,6.50,6.45,6.64,6.75,6.8$, and $6.60 \mathrm{Log}$ $\mathrm{CFU} / \mathrm{mL}$, respectively. Results are shown in Figure 1.

\section{Discussion}

As a result of the increasing resistance ability of bacteria in recent years, new approaches have gained importance in the combat against foodborne pathogens. Accordingly, our study aimed to investigate the antibacterial effects of different active substances such as $\mathrm{ZnO}-\mathrm{NPs}$, rosmarinic acid and propolis on leading food borne pathogens.

It has been reported that $\mathrm{ZnO}-\mathrm{NPs}$ produce antibacterial effects by disrupting cell morphology, generating reactive oxygen species (ROS), or creating oxidative stress (Raghupathi et al., 2011; Sirelkhatim et al., 2015). The antibacterial effect of $\mathrm{ZnO}-\mathrm{NPs}$ has been investigated in several studies so far. Navale et al. (2015) were investigated the antibacterial effect of $\mathrm{ZnO}$ in different concentrations on critical foodborne pathogens. According to their results, $60 \mu \mathrm{g} / \mathrm{mL} \mathrm{ZnO}-\mathrm{NPs}$ showed the bacteriostatic effect on target bacteria; however, $80 \mu \mathrm{g} / \mathrm{mL}$ $\mathrm{ZnO}-\mathrm{NPs}$ was found inhibitory on $S$. aureus (grampositive) and Salmonella Typhimurium (gram-negative). In another study, Manzoor et al. (2016) were observed the antibacterial effect of $<20 \mathrm{~nm} \mathrm{ZnO}-\mathrm{NPs}$ on food and waterborne pathogenic bacteria. Their investigation used $E$. coli (EPEC), Campylobacter jejuni, S. aureus (MRSA), and Vibrio cholerae as target microorganisms. The results showed that nanoparticle was efficient against all tested pathogens in different concentrations. After electron microscopy examinations, they determined that $\mathrm{ZnO}-\mathrm{NPs}$ disrupted the cellular morphology, resulting in the death of the target bacteria. Reddy et al. (2007) observed the toxicity of different concentrations of $\sim 13 \mathrm{~nm} \mathrm{ZnO}-\mathrm{NPs}$ on $E$. coli and $S$. aureus. As a result of their studies, it was determined that $\geq 3.4 \mathrm{mM}$ nanoparticles were completely inhibited the tested bacteria. Raghupathi et al. (2011) were measured antibacterial activity mechanisms of $\mathrm{ZnO}-\mathrm{NPs}$ on both gram-positive and gram-negative microorganisms (methicillin-sensitive $S$. aureus, methicillin-resistant $S$. aureus, Staphylococcus epidermidis, Streptococcus pyogenes N315, Enterococcus faecalis, Bacillus subtilis, B. cereus, Escherichia coli, Proteus vulgaris, Salmonella Typhimurium, Shigella flexinari, Pseudomonas alcaligenes, and Enterobacter aerogenes). According to their results the bacterial reduction was found nearly $95 \%$. In the mentioned studies above, the antibacterial activities of $\mathrm{ZnO}-\mathrm{NPs}$ were demonstrated at different levels. In our study, it was determined that $\mathrm{ZnO}$-NPs were showed very effective antibacterial properties on the tested bacteria. The differences between studies are due to the diameter and concentration of $\mathrm{ZnO}-\mathrm{NPs}$, different in-vitro methods, and the specific conditions of applications made.

Rosmarinic acid is a natural biologically active and phenolic antibacterial chemical that is harmless to the human body. Its antibacterial activity has been demonstrated in various investigations. Zhang et al. (2021) were revealed the antibacterial properties of rosmarinic acid in different concentrations on E. coli, Salmonella, $S$. aureus, and B. subtilis. According to their results, Salmonella and E. coli were the most resistant, and $S$. aureus and B. subtilis were the most sensitive in the tested bacteria. In another research, the antimicrobial effect of rosmarinic acid against $S$. aureus and $E$. coli was investigated, and $S$. aureus was found more sensitive (Sun et al., 2005).

\section{ZnO-NPs (10mM)}

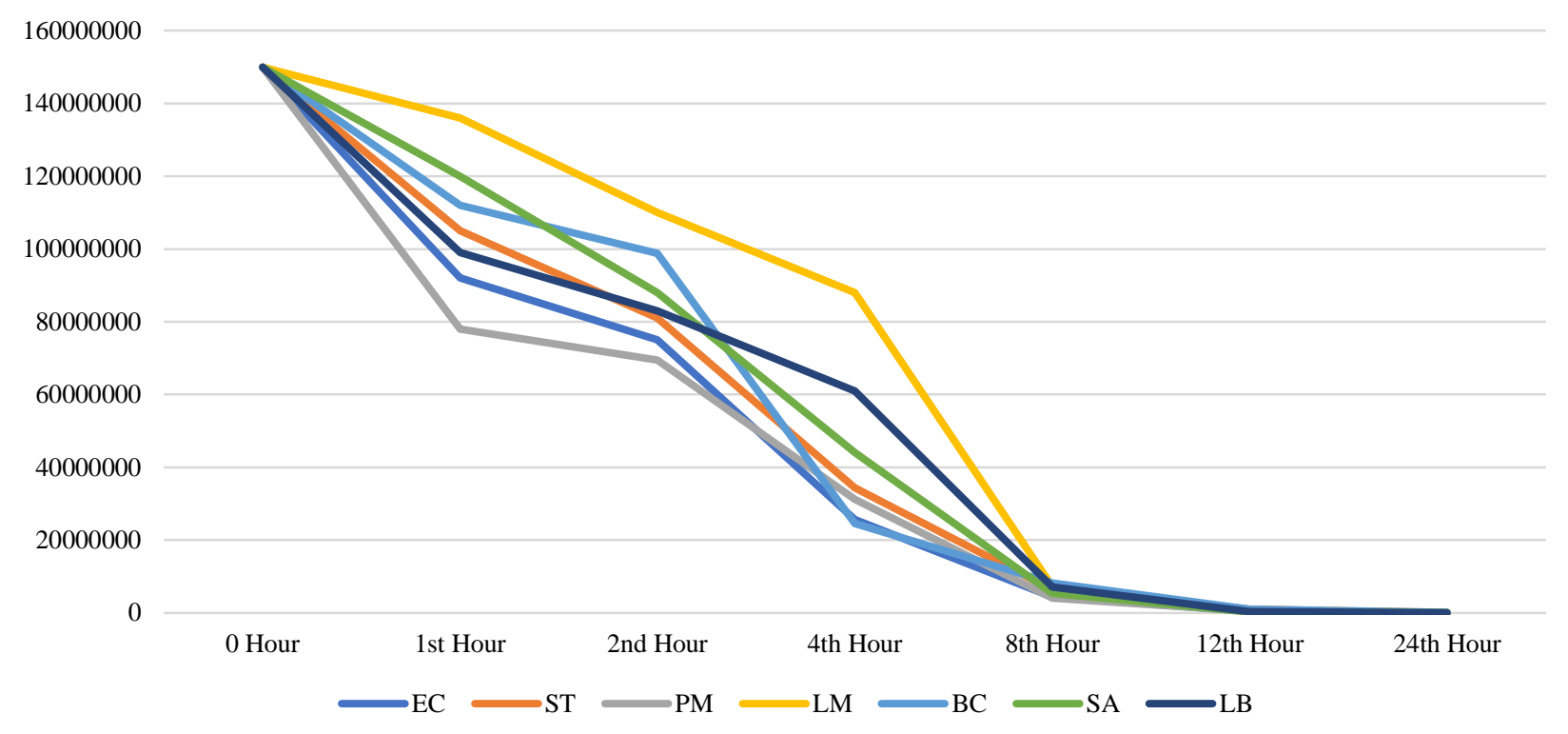




\section{Rosmarinic Acid (\%1)}

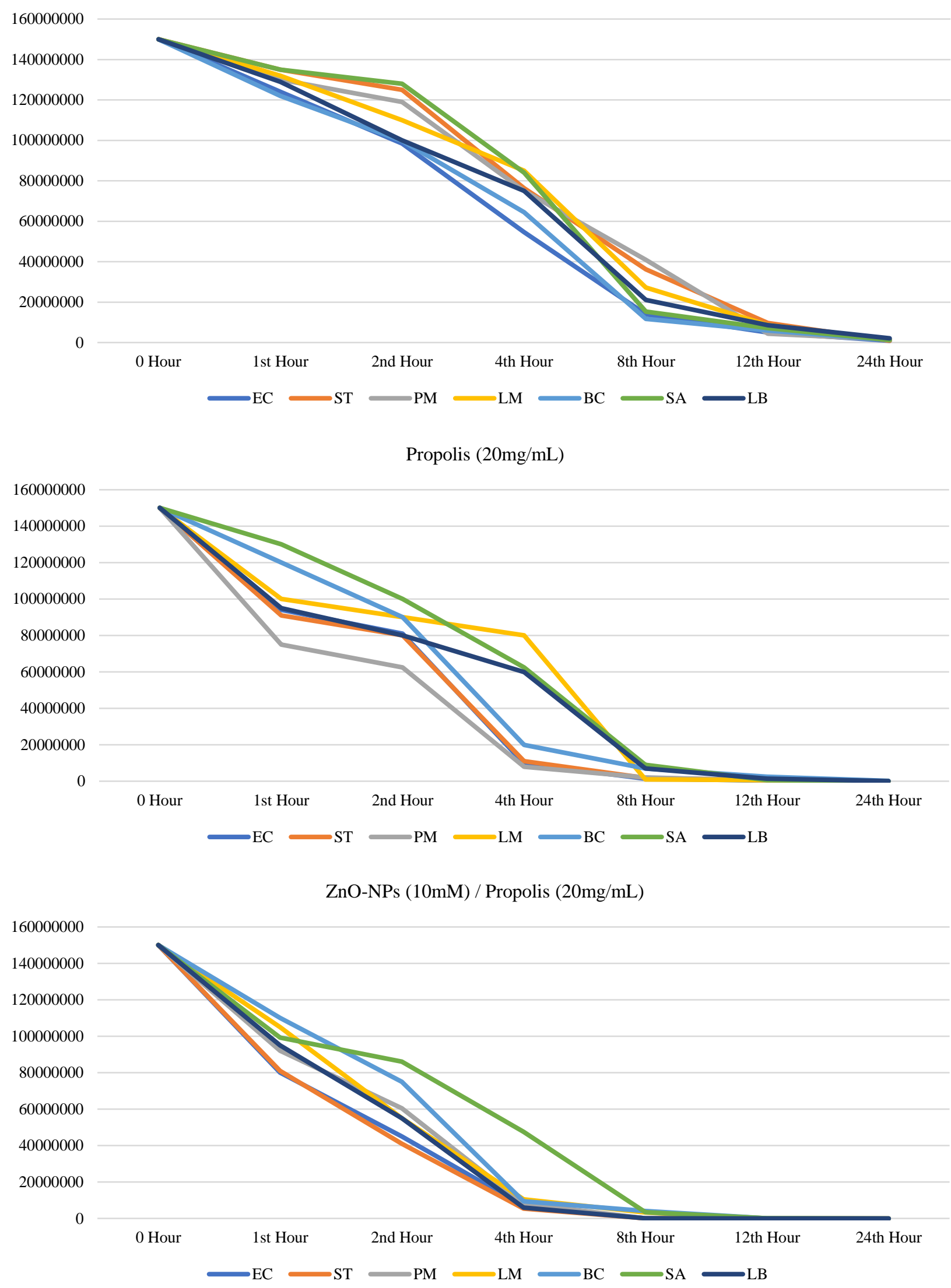




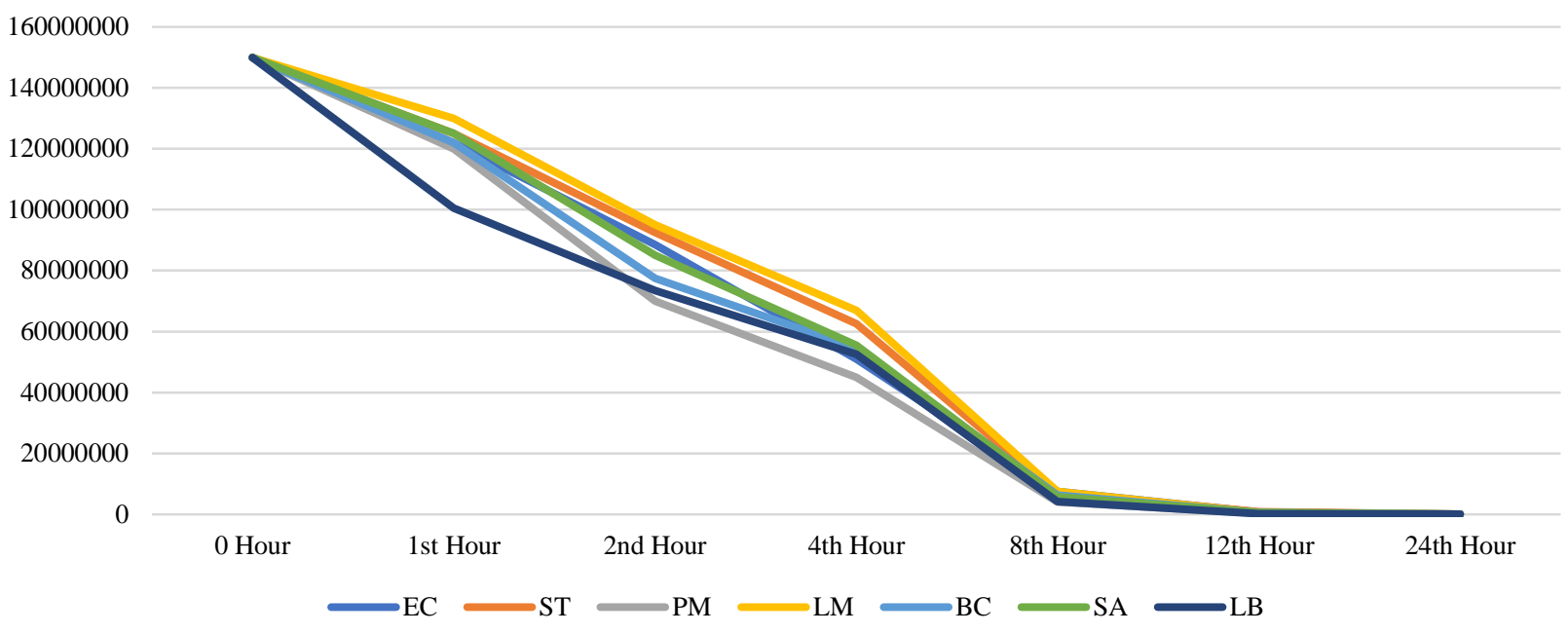

ZnO-NPs (10mM) / Rosmarinic Acid (\%1) / Propolis (20mg/mL)

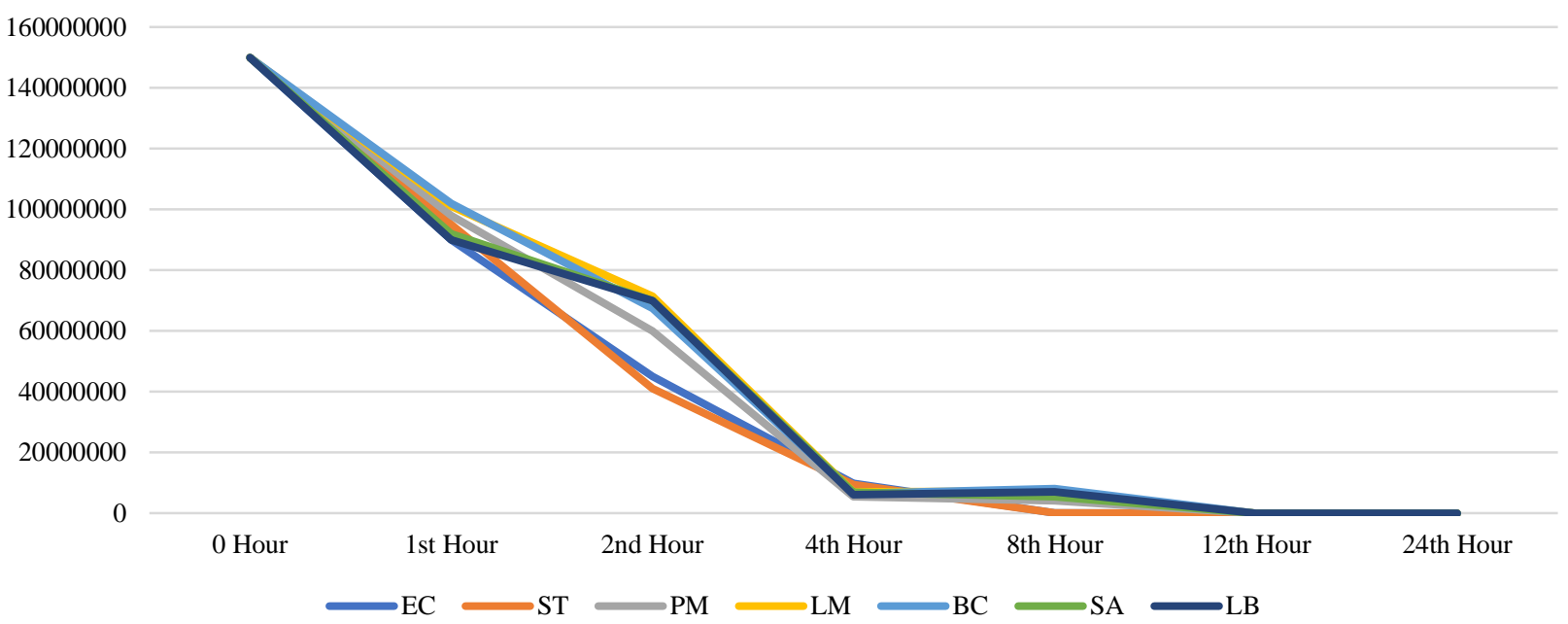

Figure 1. The invitro decontamination effect of $\mathrm{ZnO}-\mathrm{NPs}$, rosmarinic acid, propolis, and their combinations on $E$. coli O157:H7 ATCC 43895 (EC), Salmonella Typhimurium (ST), Proteus mirabilis (PT), Staphylococcus aureus ATCC 46300 (SA), Listeria monocytogenes ATCC 7644 (LM), B. cereus ATCC 10987 (BC) and Lactobacillus delbrueckii subsp. bulgaricus ATCC 11842 (LB) for 24 hours.

Cetin-Karaca and Newman (2015) were researched the bactericidal effect of rosmarinic acid on nine different foodborne pathogens (B. subtilis (ATCC 6051), B. cereus (ATCC 11778), B. polymyxa (ATCC 842), C. perfringens, C. butyricum (ATCC 8260), C. sporogenes (ATCC 7955), and three strains of L. monocytogenes) for $60 \mathrm{~h}$ (extended incubation). They reported that all tested strains were found sensitive in different levels to rosmarinic acid. However, during prolonged incubation, some strains like Bacillus, Listeria and Clostridium spp. were turned into resistant. Jordán et al. (2012) were inspected the decontamination effect of rosmarinic acid on important foodborne pathogens such as L. monocytogenes, S. aureus, Salmonella Typhimurium, and E. coli O157:H7. As stated in their work, tested gram-positive strains were more sensitive to rosmarinic acid than tested gram-negative bacteria. In the studies mentioned earlier, the antibacterial effect of rosmarinic acid has been demonstrated. The differences between studies can be explained because rosmarinic acid was prepared at different concentrations.
However, since rosmarinic acid is an antioxidant chemical, it can protect bacterial cells when prepared in high concentrations.

The antibacterial potency of propolis has been documented against microorganisms in many studies so far. The antibacterial activity of Iranian propolis on $P$. aeruginosa and $S$. aureus was investigated, and the inhibitory effect was found relatively higher on tested gram-positive strains (Aryaei and Pakzad, 2018). BucioVillalobos and Martínez-Jaime (2017) were studied the decontamination effect of Mexican propolis against Salmonella Typhimurium (ATCC-13311), E. coli (ATCC10536), S. aureus (ATCC-11632), and L. monocytogenes (ATCC-19115) in their project. According to their data, $S$. aureus and L. monocytogenes were inhibited dramatically, but no antibacterial effect occurred on Salmonella Typhimurium and E. coli. An investigation by Veiga et al. (2017) in Brazil revealed that ethanolic extracts of propolis showed a remarkable antibacterial effect on methicillinsensitive $S$. aureus and methicillin-resistant $S$. aureus. The 
activity of propolis was observed by Petruzzi et al. (2020) on some foodborne strains as Pseudomonas spp., Enterobacteriaceae, Lactobacillus plantarum, Saccharomyces cerevisiae, Debaryomyces hansenii, and Fusarium oxysporum. As stated in their research, no antibacterial effect was demonstrated against Lactobacillus plantarum. However, it has been determined that propolis provides effective decontamination on Pseudomonas spp. and Enterobacteriaceae. It is thought that conditions such as the different compositions of propolis obtained from different regions, extraction method, concentration, application method, type, and enumeration of target bacteria may affect the antibacterial activity of propolis. However, as a result of our study, it was determined that propolis obtained from Muğla/Turkey has a high antibacterial effect.

\section{Acknowledgement}

This study was supported by the University of Aksaray, Scientific Research Center, under the Project No. 2020$\mathrm{O} 25$.

\section{References}

Aryaei R, Pakzad P. 2018. Evaluation of the antibacterial activity of iranian propolis on the strains of pseudomonas aeruginosa and staphylococcus aureus. Amazonia Investiga, 7(14): 5-10.

Bharat TC, Shubham-Mondal S, Gupta H, Singh PK, Das AK. 2019. Synthesis of Doped Zinc Oxide Nanoparticles: A Review. Materials Today: Proceedings, 11: 767-775. doi: 10.1016/j.matpr.2019.03.041

Buchta V, Černý J, Opletalová V. 2011. In vitro antifungal activity of propolis samples of Czech and Slovak origin. Open Life Sciences, 6(2): 160-166.

Bucio-Villalobos CM, Martínez-Jaime OA. 2017. Actividad antibacteriana de un extracto acuoso de propóleo del municipio de Irapuato, Guanajuato, México. Agronomía Mesoamericana, 28(1): 223-227.

Cetin-Karaca H, Newman MC. 2015. Antimicrobial efficacy of natural phenolic compounds against gram positive foodborne pathogens. Journal of Food Research, 4(6): 14.

Darwish RM, Ra'ed J, Zarga MHA, Nazer IK. 2010. Antibacterial effect of Jordanian propolis and isolated flavonoids against human pathogenic bacteria. African Journal of Biotechnology, 9(36): 5966-5974

Deshmukh SP, Patil SM, Mullani SB, Delekar SD. 2019. Silver nanoparticles as an effective disinfectant: A review. Materials Science and Engineering, 97: 954-965.

Ekambaram SP, Perumal SS, Balakrishnan A, Marappan N, Gajendran SS, Viswanathan V. 2016. Antibacterial synergy between rosmarinic acid and antibiotics against methicillinresistant Staphylococcus aureus. Journal of Intercultural Ethnopharmacology, 5(4): 358.

Gupta A, Silver S. 1998. Molecular genetics. silver as a biocide: will resistance become a problem? Nature biotechnology, 16(10): 888.

ISO 4833-1. 2014. Microbiology of the food chain - Horizontal method for the enumeration of microorganisms - Part 1: Colony count at 30 degrees by the pour plate technique.

Jafarzadeh-Kashi TS, Kasra-Kermanshahi R, Erfan M, VahidDastjerdi E, Rezaei Y, Tabatabaei FS. 2011. Evaluating the In-vitro Antibacterial Effect of Iranian Propolis on Oral Microorganisms. Iranian journal of pharmaceutical research, 10(2): 363-368.
Jordán MJ, Lax V, Rota MC, Lorán S, Sotomayor JA. 2012. Relevance of Carnosic Acid, Carnosol, and Rosmarinic Acid Concentrations in the in Vitro Antioxidant and Antimicrobial Activities of Rosmarinus officinalis (L.) Methanolic Extracts. Journal of Agricultural and Food Chemistry, 60(38): 9603 9608.

Manzoor U, Siddique S, Ahmed R, Noreen Z, Bokhari H, Ahmad I. 2016. Antibacterial, structural and optical characterization of mechano-chemically prepared $\mathrm{ZnO}$ nanoparticles. PLoS One, 11(5): e0154704.

Nadeem M, Imran M, Aslam-Gondal T, Imran A, Shahbaz M, Muhammad-Amir R, Martins N. 2019. Therapeutic Potential of Rosmarinic Acid: A Comprehensive Review. Applied Sciences, 9(15): 3139.

Navale GTM, Late D, Shinde S. 2015. Antimicrobial activity of $\mathrm{ZnO}$ nanoparticles against pathogenic bacteria and fungi. Sci Med Central, 3: 1033.

Petruzzi L, Rosaria-Corbo M, Campaniello D, Speranza B, Sinigaglia M, Bevilacqua A. 2020. Antifungal and Antibacterial Effect of Propolis: A Comparative Hit for FoodBorne Pseudomonas, Enterobacteriaceae and Fungi. Foods, 9(5): 559

Raeisi M, Tabaraei A, Hashemi M, Behnampour N. 2016. Effect of sodium alginate coating incorporated with nisin, Cinnamomum zeylanicum, and rosemary essential oils on microbial quality of chicken meat and fate of Listeria monocytogenes during refrigeration. International Journal of Food Microbiology, 238: 139-145.

Raghupathi KR, Koodali RT, Manna AC. 2011. Size-dependent bacterial growth inhibition and mechanism of antibacterial activity of zinc oxide nanoparticles. Langmuir, 27(7): 40204028.

Reddy KM, Feris K, Bell J, Wingett DG, Hanley C, Punnoose A. 2007. Selective toxicity of zinc oxide nanoparticles to prokaryotic and eukaryotic systems. Applied Physics Letters, 90(21): 213902.

Shrestha B, Acosta-Martinez V, Cox SB, Green MJ, Li S, CañasCarrell JE. 2013. An evaluation of the impact of multiwalled carbon nanotubes on soil microbial community structure and functioning. Journal of Hazardous Materials, 261: 188-197.

Simone-Finstrom M, Borba RS, Wilson M, Spivak M. 2017. Propolis counteracts some threats to honey bee health. Insects, 8(2): 46.

Sirelkhatim A, Mahmud S, Seeni A, Kaus NHM, Ann LC, Bakhori SKM, Mohamad D. 2015. Review on Zinc Oxide Nanoparticles: Antibacterial Activity and Toxicity Mechanism. Nano-Micro Letters, 7(3): 219-242.

Sun X, Wang J, Li H, Du G, Guo D. 2005. A study on the antibacterial mechanism of rosmarinic acid. Journal of Qingdao University, 4: 44-48.

Veiga RS, De Mendonça S, Mendes PB, Paulino N, Mimica MJ, Lagareiro-Netto AA, Marcucci MC. 2017. Artepillin C and phenolic compounds responsible for antimicrobial and antioxidant activity of green propolis and Baccharis dracunculifolia DC. Journal of Applied Microbiology, 122(4): 911-920.

Wagh VD. 2013. Propolis: a wonder bees' product and its pharmacological potentials. Advances in pharmacological sciences, 2013: 1-11.

Zhang J, Cui X, Zhang M, Bai B, Yang Y, Fan S. 2021. The antibacterial mechanism of perilla rosmarinic acid. Biotechnology and Applied Biochemistry, 2021: 1-8

Zhuang Y, Jiang J, Bi H, Yin H, Liu S, Liu T. 2016. Synthesis of rosmarinic acid analogues in Escherichia coli. Biotechnology letters, 38(4): 619-627. 